TRANS · núm. 25.2021

DOSIER $\cdot 155-176$

Este artículo ofrece una historia de la traducción en la España de los Austrias. Se analizan las relaciones entre traducción y administración estatal a través de las estrategias y servicios de un conjunto de familias cuyos miembros participaron en la política árabe española a lo largo de múltiples generaciones. La política árabe pretendía ampliar, defender y celebrar el dominio de los Austrias españoles sobre sujetos araboparlantes en Iberia y en el Norte de África, metas inalcanzables sin un cuerpo de expertos multilingües. Este estudio descansa sobre un fondo documental manuscrito e impreso producido para promover las genealogías y la memoria colectiva de tres dinastías de traductores, lo cual permite demostrar cómo, a lo largo de los siglos xvi y xvII, la política árabe de los Austrias fue más allá de la traducción de textos árabes. Ahora bien, y como bien demuestran estas familias, dicha política no se limitó a un grupo especializado de traductores de árabe. Un abanico amplio de agentes administrativos aseguró la reputación y el dominio del Rey Católico en materias lingüísticas e historiográficas tocantes a los sujetos araboparlantes y al pasado árabe de su monarquía.

PALABRAS CLAVE: Mediterráneo, Austrias españoles, política árabe, Gracián, Venegas, presidios.

\title{
Gobernar por traducción: la memoria de los traductores estatales en la política árabe de los Austrias
}

\author{
Claire GILBert \\ Saint Louis University
}

\section{Governing by Translation: The memory of state translators in the Arabic language politics of the Spanish Habsburgs}

This article offers a history of translation in the Spanish Habsburg monarchy that focuses on the tandem of translation and state administration through the study of the strategies and services of a group of families whose members dedicated themselves to Spanish Arabic language politics over multiple generations. This language politics aimed to expand, defend, and celebrate the dominions of the Spanish Habsburgs over Arabic-speaking peoples in Iberia and North Africa. Using archival and print documents other than translations-especially those meant to promote the genealogies and collective memories of certain "translator dynasties» at the height of the seventeenth-century Spanish craze for genealogy-the Habsburg Arabic politics is shown to be much more pervasive than the (also pervasive) direct translation of Arabic documents. Arabic translators certainly contributed to Arabic politics in the Peninsula and in the Mediterranean, but they were not the only ones who ensured that the Monarchy's reputation could rely on ongoing dominion over Arabic-speaking peoples and control of a prestigious Arabic past.

KEY WORDS: Mediterranean, Spanish Habsburgs, arabic language politics, Gracián, Venegas, presidios. 


\section{INTRODUCCIÓN}

El «gobierno por palabras» de la Monarquía Hispánica - configuración compuesta de múltiples jurisdicciones además de culturas y lenguas en los siglos XVI-XVII- descansaba en gran parte sobre las espaldas de familias que a lo largo de varias generaciones se especializaron en tareas de traducción. En sí, el hecho de organizar y controlar la mediación lingüística tanto interna como externa a través de especialistas en traducción no fue una estrategia nueva para la corona y tampoco para las familias ibéricas ${ }^{1}$. En la época de los Austrias (c. 1517-1700) los mecanismos familiares de mediación se convirtieron en una herramienta política de primer orden a la par con la conversión del sistema dinástico ibérico en el seno de un imperio global.

Este artículo estudiará tres familias ibéricas cuyos perfiles complementarán nuestros conocimientos sobre otras familias de traductores en época de los Austrias debidamente analizadas, tales como los Cansino (Schaub, 1999) o los Pallache (García-Arenal y Wiegers, 2007), y traductores individuales conocidos, como Alonso de Castillo, Miguel de Luna, Aḥmad ibn Qāsim al-Hajarī y Diego de Urrea² ${ }^{2}$. A diferencia de estos traductores musulmanes, judíos, moriscos

I El estudio de los mediadores lingüísticos y políticos entre los reinos ibéricos y las poblaciones multi-confesionales de la Iberia medieval ha sido estudiado a fondo en los últimos años por, entre otros, Ana Echevarría, Ángel Galán, y Roser Salicrú. Véanse, como estudios representativos, Echevarría Arsuaga (2013), Galán Sánchez (2008) y Salicrú i Lluch (2008), entre otros muchos trabajos importantes para entender el trasfondo medieval de las cuestiones actuales discutidas en este artículo.

2 La bibliografía sobre estas figuras es amplísima; un excelente estudio reciente con una bibliografía extensa la ofrecen García-Arenal y Mediano Rodríguez (2013). y renegados que jugaron papeles fundamentales en la cultura y política árabe de los Austrias, las familias que exploramos a continuación pretendían una integración social y política plena y apuntaban a las esferas más altas del reconocimiento y los privilegios concedidos a representantes de grupos marginalizados. Estas familias alcanzaron tal estatus a través del reconocimiento de una labor lingüística conducida a través de múltiples generaciones. El servicio lingüístico de estas familias acarreaba a menudo otras actividades y todo ello alimentaba las justificaciones genealógicas sobre las cuales las tres familias mencionadas basaron su ascenso social. Dichas genealogías participaron de una moda que en el siglo XVII fomentó la competición entre oficiales del gobierno de la Monarquía (Soria Mesa, 2004: 24).

Los estudios de caso del presente artículo no han recibido la misma atención a la hora de considerar su papel lingüístico en la política árabe de los Austrias en comparación con los casos susodichos. Esto se debe principalmente al hecho de que no quedan muchos ejemplos escritos de su labor romanceadora ${ }^{3}$. No obstante, sí contamos con huellas manuscritas e impresas que dan testimonio indirecto de su labor y de la participación de los miembros de estas familias en la política árabe de los Austrias, en particular a través de sus relaciones interpersonales y de su integración política en el organigrama estatal.

Como se expondrá más abajo, la «dinastía» clave para entender la política árabe interna de la Monarquía fue la de los Venegas de Granada. En el siglo XvI los Venegas se establecieron como in-

\footnotetext{
3 Sobre los romanceadores y romanceamientos, con referencia a su bibliografía amplísima, véase 2.1 abajo.
} 
termediarios imprescindibles entre los Austrias y sus súbditos granadinos. Los Venegas consolidaron también un linaje aristocrático de servidores reales, basándose en una ya larga trayectoria de cortesanos y mediadores nazaríes desarrollada durante el siglo Xv (Seco de Lucena, 1961; Salicrú, 2001). Valiéndose de su capital social de elites inscritas tanto en el sistema castellano como morisco y teniendo en cuenta sus habilidades lingüísticas, los Venegas ayudaron a adaptar las instituciones administrativas de la corte nazarí al sistema polisinodial de la monarquía de los Austrias. Por su parte, la familia andaluza-oranesa de los Sotomayor encarnó a través de sus experiencias militares y prácticas de traducción la política árabe exterior de la Monarquía. A lo largo de los siglos XVI y XVII, esta familia de noble alcurnia compuesta por líderes militares e intérpretes construyó su propia dinastía de elites africanas en los presidios españoles del Norte de África (Corbalán, 2015; García Carraffa, 1917). Finalmente, compararemos estos dos casos de familias araboparlantes con el de una tercera familia, la de los Gracián, cuyo progenitor fue el primer secretario de interpretación de lenguas y cruzada del emperador Carlos V (Cáceres Würsig, 2004b). Tal y como hicieron los Venegas y los Sotomayor, los Gracián convirtieron el negocio de las lenguas en una herramienta política de primer orden para asegurar tanto la continuidad de la dinastía reinante como la de su propia familia. Además, sin ser araboparlantes ni diplomáticos-soldados, los miembros de esta dinastía de traductores y secretarios jugaron un papel clave y hasta ahora no reconocido en la afirmación de la política árabe de los Austrias dentro del marco global y políglota de su imperio.
1. TRADUCCIÓN Y ESTADO: LA PATRIMONIALIZACIÓN DEL PAPELEO

\subsection{La administración políglota de los Austrias}

El papeleo administrativo y los encuentros multilingües formaron parte del día a día de la práctica del imperio, con lo cual los archivos de los Austrias españoles (ca.1517-1700) han dejado un rico patrimonio para la historia de la traducción. Fueron muchas las lenguas que se hablaron en las innumerables jurisdicciones que se encontraban por debajo o al margen de la soberanía del emperador y de sus descendientes. Las relaciones internacionales reforzaron también la necesidad de mediación lingüística, oral y escrita. Estas interacciones dejaron huellas en los despachos de consejeros y ministros. Varias juntas formaron cuerpos de fuentes «extratextuales» (Munday, 2014) que hoy resultan imprescindibles para la historia de la traducción en España y para entender el papel de la traducción en la historia de España.

Una de las características más sobresaliente del gobierno de los Austrias en la monarquía hispánica fue la institucionalización del personal de lenguas dentro del organigrama de los consejos reales. Desde la llegada del rey Carlos I - cuya lengua nativa era el francés-, debida a la alianza dinástica entre Felipe de Borgoña (1478-1506), hijo del Emperador Maximiliano I, y Juana (1479-1555), hija de los Reyes Católicos, los representantes del futuro emperador obraron dentro de un sistema dinástico trans-regional y plurilingüe. Por lo tanto, los Austrias españoles y sus oficiales pensaron con cuidado la sinergia entre su estilo de gobierno y sus políticas lin- 
158 güísticas. Como punto de partida resulta fundamental referirse al trabajo de la historiadora Ingrid Cáceres Würsig, cuyo trabajo delineó los fundamentos de las tareas de los traductores estatales (Cáceres Würsig, 2004a; 2004b) ${ }^{4}$. Según esta investigadora, la innovación clave tuvo lugar al inicio del reinado de Carlos V. El Emperador instituyó el Consejo de Estado en 1527 y creó el oficio de secretario de interpretación de lenguas y cruzada, cuyo salario procedía del consejo de Cruzada (Cáceres Würsig, 2004b: 610, 621).

$\mathrm{El}$ enfoque internacional de este oficio estatal quedaba claro. Las competencias lingüísticas necesarias para gestionar la correspondencia extranjera - cifrada o no- fueron imprescindibles para la diplomacia y el logro de información política tocantes a las decisiones diplomáticas del Emperador y de su administración. Es más, al estar vinculado al Consejo de Cruzada, el secretario de interpretación de lenguas mediaba en asuntos eclesiásticos no solo internacionales sino también de suma importancia para la monarquía hispánica y su patronato en la Península misma. Por ejemplo, el nuevo secretario de interpretación de lenguas se ocupó de las traducciones de bulas, así como de la correspondencia latina del Papa relativa a la gestión del Patronato Real. Dicho Patronato derivaba de una serie de bulas medievales que concedieron varias rentas eclesiásticas extraordinarias a los reyes españoles para la «defensa de la fe» contra los musulmanes ibéricos. Bajo los reinados de Carlos V y Felipe II, el consejo de Cruzada operó tanto como una institución encargada de la «defensa de la

4 Véase en particular 2004a, 111-115, para una enumeración de los consejos que recurrieron a los servicios de los traductores. Cáceres Würsig presenta también los diferentes géneros de textos que se tradujeron durante los siglos XVI, XVII y XVIII. fe» dentro de la Península (conquista de Granada 1482-1492) como un órgano de la Hacienda Real, volcado con la expansión imperial en el Mediterráneo y en el Norte de África. Todavía en esta época, el mar Mediterráneo seguía concibiéndose como un espacio activo de las políticas de conquista y «cruzada» de los Austrias (Hess, 1971: 72-77; Rodríguez Salgado, 2008). En 1509 el cardenal Cisneros reafirmó el control real sobre estas fuentes fiscales, alegando la importancia de la conquista de Orán para seguir adelante con la empresa de cruzada (García-Arenal, 1992: 43).

El tándem fiscal-evangélico de la cruzada ibérica se extendió en la reorganización política de los Trastámara y luego de los Austrias, la cual yacía en el desarrollo de su política árabe. De hecho, fue a través de esta combinación fiscal y eclesiástica concedida por Roma y asegurado por los secretarios de interpretación de lengua como se justificaron los «diezmos de moriscos», impuestos extraordinarios sobre la población recién conquistada, y destinado en gran parte a la construcción de iglesias y pagos a eclesiásticos, que recibieron el encargo de efectuar la conquista «lingüística» del reino como parte de una campaña de evangelización (Garrido Aranda, 1979: 51). Las tropas imprescindibles para esta conquista lingüística fueron los traductores romanceadores cuya mediación en los procesos legales y fiscales permitió la reducción de gente y bienes a los sistemas de administración castellanos (Gilbert, 2018).

De modo local e internacional, la traducción generó un vínculo importante entre la formación de un Estado y la gestión económica, fiscal y lingüística de los reinos y de las experiencias y materiales árabes conectados con estos. En 1539, el mismo año que el Emperador concedió el tí- 
tulo de secretario de interpretación de lenguas, cifra y cruzada a Diego Gracián de Alderete, el Papa Clemente VII cedió al Emperador derechos de cruzada para la «defensa de la fe en el Mediterráneo» (Martínez Millán y Carlos Morales, 1991: 922) $)^{5}$. Al mismo tiempo, varios oficiales involucrados en negociaciones diplomáticas en el litoral africano y en la gestión de los presidios españoles mantenían vínculos importantes con la mediación lingüística granadina, incluyendo miembros de las familias de los Venegas y de los Sotomayor (Gilbert, 2020: 72-76). Por lo tanto, el concepto y la infraestructura de la cruzada española en Granada y en el Norte de África se vincularon a los orígenes de la secretaría de lenguas.

Durante el reinado de Felipe II ( $r$. 1556-1598) los servicios estatales de traducción siguieron institucionalizándose tanto en la corte como a través de las fronteras de la Monarquía. Durante el reinado del Rey Prudente, las prácticas de traducción se sistematizaron y las políticas lingüísticas interactuaron directamente con las políticas confesionales de la monarquía hispánica (García-Arenal 2009; Wasserman-Soler, 2020). Dentro de una monarquía de alcance global, la cuestión de la traducción e interpretación de lenguas pasó a formar parte de los cuerpos orgánicos de leyes —basados en experiencias

\footnotetext{
5 Cáceres Würsig (2004a: 51-53) sugiere que el primer nombramiento ocurrió entre 1527 y 1536. Alrededor del año 1633, Francisco Gracián Dantisco Berruguete recordaba «Que Diego Gracian Alderete abuelo del suplicante, fue secretario del señor Emperador don Carlos Quinto; como consta del título de Secretario: su fecha en Toledo a 10 de Febrero de 1539 y subcesiuamente del señor Rey don Felipe Segundo, a quien siruio en la interpretacion de lenguas, cifra, y Cruzada, y en negocios de grã importãcia, cõfiança, y secreto, assi en paz, como en guerra, por ser vnico en las lenguas, Latina, y Griega, y otras; como consta por varias certificaciones de ministros de su Mag. sus fechas desde el año de 1566 hasta el de 1578» Real Academia de la Historia (RAH), Salazar y Castro, E-21, f. 65r.
}

multilingües- que regimentaban la práctica del derecho real. En efecto, Felipe II inició varias campañas de recopilación de leyes, incluyendo las de Indias con la famosa Recopilación de Indias de 1583, confirmada por su hijo Felipe III en $1619^{6}$. Dichas recopilaciones formaron parte del marco de referencia que los traductores tuvieron a mano en el día a día de sus actividades de traducción, incluyendo el espacio imperial que se extendía más allá del Mediterráneo y en este caso, hacia el Nuevo Mundo y Asia.

\subsection{La política árabe de los Austrias}

Las lenguas del gobierno fueron muchas y no se limitaron a las europeas. Una de las áreas clave de la política lingüística imperial fue la política árabe. Los Austrias desarrollaron una política interna que consistió, por un lado, en establecer leyes y normas lingüísticas dirigidas hacía poblaciones moriscas (Vincent, 1993) y musulmanas (García-Arenal, 2009); por otro, la política árabe se manifestó a través del desarrollo de un patrimonio árabe y de una erudición arabista promovida en espacios tales como la biblioteca real del palacio-monasterio del Escorial (Hershenzon, 2019), el cual servía como una base para apoyar la reputación de la Monarquía. Así la lengua arábiga pasó a ocupar un lugar destacado en medio de las estrategias gubernamentales volcadas en la defensa, conservación y ampliación de la reputación de la Monarquía.

La política árabe de los Austrias puede definirse como el conjunto de actitudes y actividades que unió la reputación de la Monarquía y de sus territorios con poblaciones araboparlantes a

6 Libro II, Título 29, «De los intérpretes», Recopilación de leyes de los reynos de Indias. Tomo I. Madrid: Andrés Ortega, 1774. 
través del Mediterráneo, incluso en la península ibérica. Por ejemplo y empezando con las pragmáticas de Juana y de Fernando, especialmente las de 1511-1513 (Gallego Burín y Gamir Sandoval, 1968: 171-179), los reyes españoles desarrollaron un régimen lingüístico en Granada a través de la prohibición y de la traducción del árabe. Carlos V adaptó las medidas tomadas por sus antecesores. No obstante, la legislación de la época dejó un espacio suficiente para que los sujetos araboparlantes del Rey Católico negociasen con las autoridades reales las categorías socio-políticas que en la práctica los traductores debían interpretar y adaptar. A pesar de la promulgación de una política asimiladora y evangélica que descartaba el valor oficial de la lengua árabe, se mantuvo un fuerte interés político y fiscal por parte del gobierno en dejar intactas las redes comerciales y fiscales granadinas, cimentadas sobre documentos y tradiciones orales árabes (Galán Sánchez, 2016). Fue a raíz del deseo de integrar estas redes económicas como las prácticas de traducción del árabe tuvieron una razón de ser dentro de la Monarquía. Fue también dentro de este marco donde los traductores de árabe reivindicaron su talento y se distinguieron como expertos lingüísticos de primer orden.

La misma época dio paso al desarrollo de una tradición anticuaria árabe que resaltaba la intervención providencial de España en la civilización cristiana (García-Arenal y Rodríguez Mediano, 2013) para un público internacional. Felipe II (r. 1556-1598) y Felipe III (r. 1598-1621) promovieron un arabismo de índole española a la vez que impulsaban la discusión de la cuestión morisca entre sus consejeros y apoyaban la implementación de las reformas lingüísticas tri- dentinas ${ }^{7}$. La política árabe de los Austrias conjugaba la diplomacia con este arabismo español (García-Arenal, Rodríguez Mediano, y El Hour, 2002). Por ejemplo, en 1593, Felipe II fundó la primera cátedra de estudios árabes en la universidad de Alcalá de Henares. El renegado napolitano-otomano Diego de Urrea (fl. 1589-1616) fue el primero en ocupar esta cátedra (Floristán, 2013; García-Arenal y Rodríguez Mediano, 2013). En paralelo, Urrea trabajó para el Consejo de Estado en calidad de «Criado de V.Md e intérprete de los papeles Arauigos, Turquescos y Persianos» desde por lo menos $1601^{8}$.

Diego de Urrea fue uno de los primeros miembros de un nuevo cuerpo de traductores estatales que se estableció al margen de los secretarios de interpretación de lenguas a principios del siglo XVII. Los llamados «traductores de Estado» trabajaron directamente para el Consejo de Estado (Cáceres Würsig, 2004a: 141-144). Después de Urrea, el vasco Francisco de Gurmendí (m.

7 La monarquía impulsaba más de una actividad política relacionada con el árabe a la vez, incluso aunque pudiera parecer contradictoria: en primer lugar, un arabismo anticuario que promovía una visión de la historia de España gracias a la cual la corona integraba la sabiduría árabe-islámica en sus propios patrimonio e historia; en segundo lugar, una política exclusivista en cuanto a los moriscos, que en parte se distinguían por su uso de la lengua árabe o por asociarse a ideas $\mathrm{u}$ objetos que parecían mantener vínculos con el mundo árabeislámico, $y$, en tercer y último lugar, su participación en las campañas tridentinas que a la vez querían estandardizar las lenguas de la evangelización y reclamaban atención hacia las diferencias lingüísticas entre los pueblos evangelizados (de ahí las múltiples traducciones de materiales catequéticos en lenguas amerindias, árabe, etc.). El hecho es que los Austrias jugaban a la vez con y contra aspectos de la literatura, la lingüística, y la historia árabes de España para promover su estatus entre los poderes cristianos de la época.

811 septiembre, 1601. «El Consejo de Estado por Diego de Urrea.» AGS, Estado, Legajo 2741. 
1621) se hizo con el cargo de traductor de lenguas orientales (árabe, persa, otomano) en 1612 (Floristán, 2014; Cáceres Würsig, 2004a: 151). Este mismo año la Real Biblioteca del Escorial dio la bienvenida a un botín de valor inestimable: la biblioteca real del Sultán de Marruecos, Muley Zidan (Hershenzon, 2014; Zhiri, 2018). La llegada de dicha colección al Escorial coincidió con el incremento de la actividad diplomática de la Monarquía en la Persia safaví. Las colecciones de El Escorial procuraron un núcleo importante de información tocante a materias «orientales», a las que los ministros y los secretarios recurrieron para fomentar la política árabe de la Monarquía a través de la traducción (Llopis Mena, 2016). Fue en este período cuando el árabe pasó a concebirse como una lengua extranjera y, por lo tanto, su gestión se transformó aún más en un asunto de Estado y de diplomacia que de Cruzada. Este cambio de concepción relativo a la lengua árabe ocurrió de forma paralela a la expulsión de los moriscos de España (1609-1614) y al debate sobre la lengua árabe que giraba en torno a la «cuestión morisca» (Feros, 2014).

Aún después de la expulsión de los moriscos, cuando el arabismo español resultó más «fragmentado» (Rodríguez Mediano 2006), la política árabe mantuvo su rumbo a través de un servicio continuo y multigeneracional de varias familias de traductores. El árabe seguía siendo una lengua corriente y de gran utilidad profesional para la administración de los Austrias. Los traductores de árabe, que manejaban el idioma de forma rutinaria, vieron sus servicios incrementarse y, en consecuencia, se encontraron en una posición desde la cual podían pedir más mercedes y títulos a la Corona a cambio de sus servicios.

Ya bien entrando en el siglo XVII, la política árabe de la Monarquía contó con servidores pluriempleados a varios niveles institucionales y a través de diferentes espacios y territorios afines a la Monarquía. Durante el reinado de Felipe IV (r. 1621-1665), se observa cómo los oficiales ligados a la política árabe reclamaban un reconocimiento a la medida del valor de sus servicios. Utilizaron las políticas lingüísticas estatales como un mecanismo de ascenso social, mediante la composición de memoriales en los cuales pedían más favores y privilegios a la par que construían sus historias familiares y linajes profesionales al servicio de la Monarquía.

\section{GENEALOGÍAS LINGÜÍSTICAS A TRAVES DE LA POLÍTICA ÁRABE DE LOS AUSTRIAS}

Desde la época medieval la corte real y sus chancillerías proveían espacios para el desarrollo de una administración políglota. En época de los Austrias, la traducción real pasó también a ser un instrumento clave para los sistemas interimperiales de representación del poder real. De un lado, la traducción y la gestión del lenguaje consolidaron la integración de nuevos territorios y comunidades en la Monarquía Católica. De otro, y frente al espejo de las políticas dinásticas llevadas a cabo por otros Estados modernos, las actividades traductoras dentro de la corte española colocaron a ciertas familias al frente de los despachos de lenguas. Los tres casos aquí estudiados sirven y servían de ejemplos para entender las raíces comunes de la mediación lingüística y la política árabe de los Austrias. 
TABLA 1. Las ascendencias directas de intérpretes mencionadas en este estudio

\begin{tabular}{|c|c|c|c|c|c|}
\hline $\begin{array}{l}\text { Los trujamanes de } \\
\text { Granada }\end{array}$ & \multicolumn{2}{|c|}{ Los intérpretes-lenguas de Orán } & \multicolumn{3}{|c|}{ Los secretarios de interpretación de lenguas } \\
\hline $\begin{array}{l}\text { Yahyà al-Nağğār, } \\
\text { dicho Pedro de Gra- } \\
\text { nada (1442-1506) } \\
\text { padre de }\end{array}$ & \multicolumn{2}{|c|}{ Luís Álvarez de Sotomayor (fl. 1523) ${ }^{10}$} & \multicolumn{3}{|c|}{ Juan Dantisco (1485-1548), cuya hija natural se casó con } \\
\hline $\begin{array}{l}\text { 'Alī ‘ Umar ibn Nașr, } \\
\text { dicho Alonso Venegas } \\
(1467-1539)^{11} \text {, abuelo } \\
\text { de }\end{array}$ & \multicolumn{2}{|c|}{$\begin{array}{l}\text { Gil Álvarez de Sotomayor (m. anterior } \\
1601)^{12} \text {, padre de }\end{array}$} & \multicolumn{3}{|c|}{ Diego Gracián de Alderete (c. 1494-1586), padre de } \\
\hline $\begin{array}{l}\text { Alonso de Granada } \\
\text { Venegas Renfigo (m. } \\
1611)^{13} \text {, padre de }\end{array}$ & $\begin{array}{l}\text { Gil Hernández } \\
\text { de Sotomayor } \\
(\text { fl.1601-1612) })^{14} \mathrm{y}\end{array}$ & $\begin{array}{l}\text { Fernando de Navarrete } \\
\text { y Sotomayor (fl. } 1612 \text { - } \\
1632)^{15} \text {, padre de }\end{array}$ & $\begin{array}{l}\text { Antonio Gra- } \\
\text { cián Dantisco } \\
\text { (c.1540-1576), }\end{array}$ & $\begin{array}{l}\text { Jerónimo Gracián } \\
\text { Madre de Dios } \\
(1545-1614) \text { y }\end{array}$ & $\begin{array}{l}\text { Tomás Gracián } \\
\text { Dantisco } \\
\text { (1558-1621), } \\
\text { padre de }\end{array}$ \\
\hline \multirow[t]{2}{*}{$\begin{array}{l}\text { Pedro de Granada } \\
\text { Venegas Manrique de } \\
\text { Mendoza (1559- } \\
1643)^{16} \text {. }\end{array}$} & \multicolumn{2}{|c|}{$\begin{array}{l}\text { Gil de Navarrete Sotomayor y Valenzuela }{ }^{17} \\
(1607-\text { c.1660), padre de }\end{array}$} & $\begin{array}{l}\text { Alonso Gracián } \\
\text { Berruguete (fl. } \\
\text { 1626-1636) y }\end{array}$ & \multicolumn{2}{|c|}{$\begin{array}{l}\text { Francisco Gracián Berruguete (fl. } \\
\text { 1636-1678), padre de }\end{array}$} \\
\hline & \multicolumn{2}{|c|}{$\begin{array}{l}\text { Francisco Fernández de Navarrete (fl. } \\
\text { 1643-1660). }\end{array}$} & \multicolumn{3}{|c|}{ Antonio Gracián Gutiérrez (fl. 1678-1700) ${ }^{18}$. } \\
\hline
\end{tabular}

9 Alcaide de Baza en época nazarí y luego capitán en los ejércitos de los Reyes Católicos. El primer miembro de la familia que llevó el hábito de Santiago. «Noticias genealógicas de la casa de Granada Venegas». RAH C-41 (Salázar y Castro), ff. 262-263.

Io Corbalán de Celis y Durán, 2015, se concentra sobre la otra rama de la familia Álvarez de Sotomayor (la ascendencia del hermano de Gil Álvarez, Luis Álvarez), cuya trayectoria en los presidios africanos corre paralela a la de los Sotomayor y ocasiona a la postre al ennoblecimiento de Martín Álvarez de Sotomayor y Soto-Flores (1723-1819) como I Conde de Colomera.

II Regidor y alguacil mayor de Granada. Real Academia de la Historia, D-25 (Salazar y Castro), f. 13v. También trujamán mayor de Granada, como su padre en «tiempos de moros». Archivo General de Simancas (AGS), Registro General del Sello (RGS), leg. 1494-II.

I2 Se casó con Leonor de Navarrete, natural de Orán. Véase la genealogía en la expediente de pruebas de 1643 de Gil de Navarrete y Sotomayor (abajo, nota 17).

I3 No consta que su padre, Pedro de Granada Venegas de Mendoza (1502-1565), actuara de forma reconocida en el mundo de la traducción-interpretación. No obstante, Pedro de Granada Venegas continuaba el servicio político y militar de su familia en el ámbito multilingüe de Granada, además de patrocinar una academia literaria de gente interesada en varias lenguas por fines eruditos o artísticos, tal y como Diego Hurtado de Mendoza y Mira de Amescua (González Vázquez, 2010: 417).

I4 «Informe sobre el oficio de intérprete de la lengua arábiga en Orán por Felipe Prieto Valenzuela.» (1633) RAH Salazar y Castro K-64, ff. 93r-95r.
I5 Se casó con María Ana de Valenzuela, natural de Orán. Véase la genealogía en la expediente de pruebas de 1643 de Gil de Navarrete y Sotomayor (abajo, nota 17).

16 Primer Marqués de Campotéjar en 1643. Véanse los documentos en García Luján (2010b).

${ }^{17}$ La genealogía de Gil [Fernández] de Navarrete y Sotomayor se encuentra en AHN OOMM Caballeros-Santiago, exp. 2997, f. 6r, además de los testimonios del expediente. También queda mucha documentación sobre las actividades de este Gil y su hijo Francisco Fernández de Navarrete en la colección Altamira, especialmente en los fondos de la Biblioteca Zabálbaru y de la British Library. En particular, véase «Orden a los Oficiales Reales, en 18 de Febrero [1655], para que a Don Francisco Fernández de Navarrete, alferez de la Compañía de infanteria del Capitan Gabriel Ponze de León, é hijo mayor del D. Gil Fernandez de Navarrete y Sotomayor, interprete mayor de la lengua arabiga, se le siente plaça de dicha lengua». BL Add. Mss. 28,440, f. 77. No obstante, Gil Fernández de Navarrete y Sotomayor sigue actuando en capacidad de intérprete mayor hasta por lo menos finales de 1660. Véase «El Duque de San Lucar, Marques de Liganes, a Don Gil Fernandez Navarrete y Sotomayor». Orán, 28 Octubre, 1660, y respuesta Orán, 31 Octubre, 1660. BZ Miro 534,1-2.

I8 También padre de los últimos Gracianes, secretarios de interpretación de lenguas: Felipe Gracián y de Pereda (fl. 17021714) y Francisco Gracián y de Pereda (fl. 1714-1734). (Cáceres Würsig, 2004b: 67-69). 


\subsection{Los trujamanes mayores: los Venegas de Granada}

Los Reyes Católicos ya habían empezado a promover un gobierno basado en el arte de la traducción. En el nuevamente conquistado reino de Granada, por ejemplo, testamentos, recibos, pagos, leyes, inventarios, juramentos y otros papeles relacionados con la administración de lo cotidiano, quedaron vigentes en sus versiones originales escritas en árabe a través de su «romanceamiento» al castellano ${ }^{19}$. Este proceso de «romanceamiento» de documentos árabes consolidó la implementación de una política árabe cuyo objetivo principal fue la incorporación de la memoria judicial-administrativa musulmana en el cuerpo documental y oficial castellano. Según Galán Sánchez (2016: 17), «la hacienda regia funcionaba aprovechando la experiencia del Estado nazarí y las habilidades de sus antiguos agentes fiscales». De este modo, el incipiente Estado español de los Austrias se aprovechaba de las relaciones interpersonales forjadas dentro del antiguo mundo nazarí, de la política lingüística de los Trastámaras y de la diplomacia mediterránea renacentista. Por ejemplo, y para asegurar la integración política y lingüística del reino de Granada, Fernando e Isabel se apoyaron en las instituciones y en el personal nazaríes, entre los cuales figuraban dos miembros de la familia Venegas: Yahyyà al-Nağğār, el padre, y 'Alī 'Umar ibn Nașr, el hijo. La familia Venegas constituía un linaje de nobles andaluces cristianos que fue incorporándose a la elite gubernamental nazarí en el siglo XV (Seco de Lucena, 1961). A finales del siglo Xv, los Venegas se ocupaban de una de las secretarías de lenguas de los

\footnotetext{
I9 Unas recensiones de la bibliografía vasta sobre los romanceamientos se encuentran en Molina López y Jiménez Mata, 2004; Feria y Arias, 2004, y Gilbert, 2018a.
}

sultanes granadinos. 'Alī se convirtió al cristianismo en 1489 y pasó a llamarse Alonso Venegas. En 1494, recibió el título de «trujamán mayor», remplazando a su padre, Yahyà, y así aseguró la continuidad profesional de su familia desde «tiempos de moros» $»^{20}$. Al recibir este nombramiento por parte de las autoridades castellanas, Alonso heredó un cargo que había sido tradicionalmente asociado al gobierno musulmán del reino de Granada.

Alonso Venegas ocupó de manera simultánea el cargo real de trujamán mayor y un cargo municipal en calidad de regidor del cabildo de Granada y alguacil general (García Luján, 2010a). A través de estos oficios, Alonso formó equipos de traductores-intérpretes (entre los cuales figuraban moriscos, conversos y otros) para cumplir las tareas necesarias del «gobierno por traducción $»^{21}$. Estos oficiales 1) llevaban a cabo repartimientos, empadronamientos y levas de impuestos, 2) facilitaban los votos de los regidores araboparlantes y 3 ) colaboraban con el gobierno militar del alcaide de Granada, Íñigo López Hurtado de Mendoza, Conde de Tendilla. Dicha colaboración con araboparlantes era imprescindible para llevar a cabo otros proyectos reales más allá de Granada. Por ejemplo, tanto el Conde de Tendilla como Alonso Venegas participaron en la conquista de Orán en 1509. A la par,

\footnotetext{
${ }^{20}$ «Merced del cargo de trujamán mayor de los moros a don Alonso Vanegas, contino, con los mismos derechos que se llevaron en tiempo de los Reyes moros de Granada, los cuales se especifican», Archivo General de Simancas (AGS), Registro General del Sello (RGS), leg. 1494-II.

${ }^{21}$ Por ejemplo, en 1500 el cabildo de Granada autorizó 280 maravedíes para cuatro burros que iban a portar dos equipos de traductores -incluso el mismo don Alonso Venegas - para entrevistar y observar las poblaciones rurales para el empadronamiento. Registro del Cabildo diciembre 10, 1500, M.A. Moreno Trujillo, La memoria de la ciudad: El primero libro de actas del cabildo de Granada (1497-1502), Madrid: 2005. Doc. 221, f. 166v-167r, pp. 374-375.
} 
164 Alonso y los traductores de árabe 4) facilitaron la «misión morisca» y promovieron proyectos evangelizadores e inquisitoriales en Granada y en el Norte de África. Debieron también 5) prestar asistencia al personal de la chancillería real en Granada, ya que fue en esta institución donde se procesaban los documentos, los testimonios y los pleitos previamente redactados en árabe (Feria y Arias, 2005; Abad Merino 2011). A través del caso de los Venegas, el proceso de institucionalización del trujamán mayor de Granada tuvo lugar al mismo tiempo que Carlos V nombró su primer secretario de interpretación de lenguas ( $\mathrm{y}$ justo después de la visita matrimonial del emperador a Granada en 1526), con su mandato doble de coordinar la traducción diplomática imperial y ayudar al consejo de Cruzada. En el teatro granadino y en el corazón de la administración imperial, la labor traductora estaba asociada a «la defensa de la fe» y a las políticas internacionales de la Monarquía en escenarios variopintos como eran el Imperio Habsburgo y el Mediterráneo.

Alonso Venegas utilizó sus cargos, su prestigio local y su experiencia al frente de negociaciones políticas que tuvieron lugar en los espacios fronterizos del Norte de África para facilitar la integración jurídica de poblaciones y territorios recién conquistados por la Monarquía Católica. Los Venegas facilitaron un recurso fundamental para dicha conquista: sus miembros tendieron puentes entre elites locales (que contaban con sus propias redes clientelares) y la corte. Teniendo en cuenta su estatus social, sus capacidades lingüísticas y sus experiencias y contactos a todos los niveles de la sociedad granadina, Alonso Venegas actuó como representante de la ciudad en las Cortes de Castilla de 1520. Bajo su mando, el cargo de trujamán mayor ganó en importancia administrativo-política y la figura del traductor real adquirió visibilidad dentro de la administración de la Monarquía. Alonso pasó su título en 1536 al romanceador Juan Rodríguez, quien controló el oficio hasta su muerte en 1554 (López Nevot, 2010: 343).

Durante su larga historia de servicios lingüísticos, los Venegas no solo se ocuparon de la traducción árabe-romance. Fomentaron también prácticas eruditas relacionadas con el manejo de lenguas, especialmente el latín y el romance. La Academia de los Granada Venegas se estableció en Granada alrededor de 1560 y perduró hasta en torno a 1610 (González Vázquez, 2010: 417). Esta academia informal contó con representantes de la traducción humanística de la época, entre ellos el humanista granadino Juan Latino, cuyo elogio a don Juan de Austria fue un reflejo de la política árabe mediterránea llevada a cabo por los Austrias entre Lepanto y las Alpujarras (Wright, 2009). La «tertulia» multigeneracional de los Venegas acogió también traductores de árabe como Luis del Mármol Carvajal y Miguel de Luna. Mercedes García-Arenal y Fernando Rodríguez Mediano demostraron que las actividades humanísticas de la academia de los Granada Venegas fomentaron debates alrededor de uno de los episodios más importantes de la historia de la traducción árabe en la España moderna, el de los Plomos de Granada (García-Arenal y Rodríguez Mediano, 2013: 88-91). Valiéndose de su academia, los Venegas facilitaron el intercambio de textos árabes, tales como los del embajador y autor de la Guerra de Granada, Diego Hurtado de Mendoza, cuya biblioteca arábiga acabaría en las colecciones reales del palacio-monasterio del Escorial (Morata, 1934: 90), gestionado por Antonio Gracián, hijo de Diego Gracián de Alderete, primer secretario de interpretación de lenguas nombrado por Carlos V. Después o, mejor dicho, en paralelo a sus servicios como «intérpretes prácticos» de la lengua arábiga, los Venegas se presentaron como una familia interesada en el cultivo erudito y humanista de lenguas tales 
como el latín o el árabe y de las culturas asociadas con estas en el ámbito granadino.

Los Venegas contribuyeron también a la integración de nuevos territorios y poblaciones en la Monarquía mediante los servicios militares que prestaron al rey católico. Estos servicios formaron parte de la estrategia que la familia siguió para consolidar su nobleza. Además de los servicios que prestaron a la monarquía durante la conquista de Orán, fue a lo largo de la rebelión de las Alpujarras y de la guerra de Granada (1568-1571) cuando los Venegas trabajaron como intérpretes revestidos de cargos militares. Por ejemplo, el nieto de Alonso Venegas, Alonso de Granada Venegas Renfigo, se alzó al rango de capitán de la caballería de don Juan de Austria (1547-1578) en Granada. En paralelo, actuó repetidas veces como intérprete de lengua árabe entre las fuerzas castellanas y los rebeldes moriscos ${ }^{22}$. Desde su punto de vista la política árabe de los Austrias se basaba tanto en la gestión de traducciones como en el manejo diplomático de la violencia. En la práctica, traducción y estrategias de gestión de la violencia bajo los Austrias constituían dos caras de la misma moneda.

No fue antes de mediados del siglo XVII cuando la labor lingüística de la familia fue justamente correspondida mediante la concesión de nuevos privilegios y derechos. Aunque eran aristócratas «cristianos viejos de moros» y señores de Campotéjar desde 1492, los Venegas no se hicieron con un título nobiliario de alto nivel antes del advenimiento de su cuarta generación. Don Pedro de Granada Venegas Manrique de Mendoza (1562-1649) —hijo del mismo Alonso de Granada Venegas Renfigo que luchó y llevó a cabo tareas

\footnotetext{
22 Diego Hurtado de Mendoza, Guerra de Granada, que hizo el rey don Felipe II contra los moriscos de aquel reyno, sus rebeldes, «que se avia platicado» [nota marginal de la época]: «por don Alonso de Granada Venegas» con los moros», BnF, Espagnol 3341619 , f. $96 \mathrm{v}$.
}

de traducción en las Alpujarras - recibió el títu165 lo de Marqués de Campotéjar por parte de Felipe IV en 1643. Entre las líneas del texto mediante el cual se le confirió el título en 1643 aparece la larga serie de servicios lingüísticos prestados por los Venegas. Felipe IV describe cómo Yahyà alNağğār, el padre de Alonso Venegas, recibió por parte del rey Fernando el Católico «las capitulaçiones de Granada originales de la entrega de Granada para su cumplimiento». Estas capitulaciones habían sido objeto de un minucioso trabajo de composición y traducción llevado a cabo por el colega de al-Nağğār, el trujamán judío Simuel Abenatuel (Baeza, 1868: 40). Se comprueba aquí cómo los Venegas usaron su currículo familiar relacionado con la política árabe de los Austrias para pedir mercedes y privilegios. Tal y como lo hicieron su padre, abuelo y bisabuelo, Pedro de Granada Venegas sirvió en los ejércitos reales y tuvo a su cargo tropas originarias de Granada. Representó a la ciudad de Granada en las Cortes de Castilla entre 1609 y 1614. Reforzó su autoridad al presentarse como traductor entre la Monarquía, las autoridades municipales y la población granadina, que ya no era araboparlante después de las campañas de repoblación de 1571 llevadas a cabo por la Corona.

Con la elevación social de los Venegas, la memoria de la familia y de sus servicios lingüísticos pasaron a formar parte integral de la memoria colectiva de una monarquía compuesta y políglota. En el nombramiento de 1643, Felipe IV no dudaba en referirse a Yahyà y a 'Alī 'Umar a la hora de subrayar la importancia de los servicios de la familia mediante oficios reales y municipales:

Y teniendo consideraçión a la antigüedad de vuestra Casa y su calidad y a lo que vuestros asçendientes han seruido a mi Corona Real, siendo como sois quinto nieto del Rey Juseph Albenamavl Alnayar, Rey de Granada, aliado que fue del señor rey don Juan segundo, desçendiente por varón del 
Rey Abetlud que mataron en Almería, del linaje de los reyes de Çaragoza, y de don Pedro de Granada, vuestro rebisabuelo, que mouido de espíritu diuino tomó nuestra santa fee católica (García Luján 2010a: 84-88).

Al conceder el título de Marqués de Campotéjar, Felipe IV se apoyó en la genealogía de los Venegas para fortalecer la reputación de su monarquía. El ennoblecimiento de los Venegas favoreció el traslado de la memoria de la familia, incluyendo su labor lingüística y reconocimiento de sus raíces reales nazaríes y trastámaras, en la memoria colectiva y elitista inventada por los Austrias y sus historiógrafos.

La trayectoria de los Venegas ilustra cómo la labor lingüística de ciertas elites fue reconocida y aprovechada por el gobierno de los Austrias en su política árabe mientras la familia ascendía por la escala social dentro del aparato administrativo de la Monarquía. La labor lingüística llevada a cabo por la familia Venegas durante la conquista y «reducción» de Granada, a través de la expansión militar de los Austrias en el Mediterráneo $\mathrm{y}$, finalmente, a través del afianzamiento de una cultura académica granadina, constituyó uno de los componentes más importante del proceso de consolidación de la soberanía de los Austrias en Granada, especialmente después de la expulsión de los supuestos últimos súbditos araboparlantes nativos del reino. No obstante, la política árabe de los Austrias implicaba tanto la gestión de asuntos exteriores como interiores de la Monarquía y toca analizar trayectorias paralelas a los Venegas que tuvieron lugar desde el otro lado del Mediterráneo.

\subsection{Los intérpretes-lenguas de árabe: Los Sotomayor de Orán}

De forma paralela al desarrollo de la política árabe interna y a la apropiación de la memoria de familias tales como la de los Venegas por parte de los Austrias, la dinastía llevó a cabo una política árabe en el Norte de África a través de sus presidios. La diplomacia con poderes locales y las relaciones trans-imperiales con poderes otomanos o marroquíes reforzaron el prestigio y el carácter internacional de la política árabe de los Austrias.

A pesar de su distancia con la península ibérica, los presidios fueron una extensión del sistema gubernamental de la Monarquía Hispánica. La administración real precisaba de un órgano de traducción en estos territorios para asuntos prácticos y de representación política. Es bien sabido que en Orán, pieza clave del sistema de presidios en el norte de África, la política árabe dependía de una red de traductores sefardíes que se mantuvo hasta 1669 (Schaub, 1999).

Ahora bien, familias cristianas, incluidos los Sotomayor, también se habían hecho con el cargo desde mediados del siglo $\mathrm{XVI}^{23}$. Los Sotomayor descendían del linaje de una familia cristiana andaluza cuya presencia en el presidio remontaba a principios del siglo XVI (Corbalán, 2015: 16). Sus miembros ganaron experiencia al lado de los Cansino y Sasporta, hasta la expulsión de la comunidad judía de Orán en 1669, como bien reflejan los memoriales co-redactados que escribieron los «intérpretes de lengua arabiga» de la plaza ${ }^{24}$. De hecho, uno de los motivos utilizados para justificar la expulsión de los judíos de Orán correspondió con el auge de la actividad profesional de los Sotomayor (Gilbert, 2020: 96-100). Había quedado claro que

23 Felipe Prieto Valenzuela, «Informe sobre el oficio de intérprete de la lengua arábiga en Orán» (1633), RAH, Salazar y Castro, K-64, ff. 93-95.

${ }^{24}$ Véase, por ejemplo, RAH, Salazar y Castro, K-65, «Relación de las dos jornadas que el Sr. Marqués de Flores Dávila, del Consejo de Guerra de su Mad., \&\&, hizo el mes de Mayo deste presente año de 1635 . Original, firmado por el capitán Gil Fernández de Navarrete y Sotomayor, y Yaho Çaportas, intérpretes de la lengua árabe», ff. 178r-v. 
- desde la perspectiva de ciertas elites cristianas del Presidio- la influencia alcanzada por estas familias judías en materia de mediación multilingüe debía limitarse para afianzar el control cristiano sobre los asuntos del presidio (Sotomayor, 1670: 4v). No es accidental que el autor de la Breve relación y compendioso epitome de la general expulsión de los Hebreos de la Iuderia de Orán (1670) — donde se explicaba que dicha expulsión había sido necesaria para conservar la reputación de la monarquía en contra de una amenaza procedente del cuerpo de traductores judíos- fuese un tal capitán Luis Joseph Sotomayor y Valenzuela, también miembro del árbol entremezclado entre las familias oranesas de los Navarrete, Sotomayor y Valenzuela $\mathrm{a}^{25}$.

Las estrategias familiares de los Sotomayor no se limitaban a entremezclar rivalidades profesionales con la política de la monarquía y su reputación. Ya a las alturas de los años treinta del siglo XVII los Sotomayor se encontraban al frente de una dinastía mediterránea de traductores oficiales. Esta dinastía contaba con capitanes de compañías de soldados, gobernadores de presidios y consejeros reales (García Carrafa y García Carrafa, 1917: 134-136). En 1631 el capitán Fernando Navarrete de Sotomayor sirvió como gobernador interino del presidio de Larache, en la costa atlántica de Marruecos (García Figueras

${ }^{25}$ A principios del siglo XVII establecieron vínculos matrimoniales con la familia de los Valenzuela y los primos Navarrete y Sotomayor y Álvarez de Sotomayor (dos ramas descendientes de los originales Sotomayor, que se implantaron en el presidio después de la llegada de Luis Álvarez de Sotomayor en los 1520s). Fernando de Navarrete y Sotomayor -intérprete de lengua árabe en Orán- se casó con María Ana de Valenzuela mientras que su primo Hernán de Álvarez de Sotomayor se casó con Isabel de Valenzuela. Véase los expedientes de pruebas de la siguiente generación, Gil Fernández de Navarrete y Sotomayor y de Valenzuela (AHN OOMM, CS, exp. 2997) y de Luis Sotomayor y Pérez de Navarrete (AHN OOMM, CS, exp. 7880), los dos aprobados en 1643. y Rodríguez Joulia de Saint Cyr, 1973: 182-185), después de haber servido como «lengua e intérprete de arábigo» en Orán entre 1612 y 1618 debido al fallecimiento de su hermano Gil (RAH Salazar y Castro K-64, 1633: f. 93v). En 1632, Fernando ocupó su nueva posición en Larache y el cargo de intérprete pasó en las manos de su hijo, también llamado Gil Hernández de Sotomayor, quien recibió el título oficial este mismo año ${ }^{26}$. En 1643, al mismo tiempo que los Venegas obtenían su marquesado, Gil Fernández de Navarrete y Sotomayor y de Valenzuela, lengua e intérprete de arábigo, capitán de CaballosLanzas españolas en Orán y luego gobernador del Peñón de Vélez de la Gomera, pidió y recibió un hábito de Santiago ${ }^{27}$. De la misma manera que Pedro Venegas, Gil Fernández construyó un linaje de oficiales especializado en el servicio lingüístico de la Monarquía ${ }^{28}$. En 1654, Felipe IV escribió al gobernador de Orán para favorecer a la familia con un título de intérprete mayor concedido a Francisco de Navarrete, hijo de Gil

${ }^{26} \mathrm{RAH}$, Salazar y Castro, K-65, «Razón que por orden del señor marqués de Flores Dávila, del Consejo de Guerra de su Magestad, que por su mandado sirve el cargo de Gobernador y Capitán General de las plazas de Orán y Mazalquivir y reinos de Tremecén y Túnez, hemos hecho Don Gil Fernández de Navarrete y Sotomayor, capitán de ynfantería española y Aaron Cansino, lenguas intérpretes de la arábiga en ellos por el Rey nuestro Señor. Trata de la reunión que tuvieron los moros, vasallos de España, en la alcazaba de Orán, para fijar el precio de la romia de trigo, el año 1632,» ff. 214r-215v. Felipe Prieto Valenzuela indica que se había ejercido del oficio ya desde 1629 (RAH Salazar y Castro K-64, 1633: f. 93v).

${ }^{27}$ Gil Fernández de Navarrete y Sotomayor y de Valenzuela, AHN Ordenes Militares, Expedientes de Pruebas de los Caballeros de Santiago, Expediente 2997 (Caja 578) [1643]. El consejo de órdenes aprobó la petición el 30 de mayo, 1643.

${ }^{28}$ Por ejemplo, un testigo que apareció en una petición de 1643 juró conocer al abuelo de Gil Fernández de Navarrete y Sotomayor y de Valenzuela, «que se llamaba Capitan Gil Fernandez de Sotomaior q lo fue de caballos y lengua interprete de su magestad como lo son su nieto y lo fue su hijo» (f. $3 r$ ). 
168 Fernández, también caballero de Santiago y luego gobernador del presidio de Peñón de Vélez ${ }^{29}$.

La política árabe de los Austrias dependía de una red de administradores posicionados en entornos urbanos y fronterizos tales como Granada y los presidios del Norte de África. En estos dos ámbitos los traductores de árabe participaron de lleno en la gestión de la frontera mediterránea. Frontera que fue pensada como espacio de intercambios, conflictos y negociaciones cuyas barreras lingüísticas fueron muy porosas gracias al multilingüismo, al manejo de formas de comunicación como la lingua franca (Dakhlia, 2008) y al trabajo de dichos traductores. Esta frontera no fue «olvidada» por la monarquía y tampoco por los administradores ubicados en la Corte. Más bien, esta frontera fue una pieza clave en la política árabe de los Austrias, así como por los traductores y sus familias.

\subsection{Los secretarios de interpretación de len- gua: los Gracián de la Corte}

Mientras los Venegas y los Sotomayor, entre otros, participaban a la política árabe de los Austrias a través de sus interacciones y negociaciones multilingües, asegurando así la integración de poblaciones y territorios ibéricos y mediterráneos, otra dinastía de traductores respaldó desde el centro gubernamental de la monarquía dicha política. Los Gracián se implicaron en la

\footnotetext{
${ }^{29}$ British Library, Additional MSS, 28, 441, f. 221 «Hase visto lo que referi en despacho de veinte y ocho de Jullio, en orden a la $\mathrm{m}[\mathrm{e}] \mathrm{r}[\mathrm{ce}] \mathrm{d}$ que el año de seiscientos treinta y siente hiçe a Dn Gil de Nauarrete, del Officio de Interprete mayor de la lengua Arauiga en essas Plaças, para el hijo que nombrasse, y la suspension desta gracia, por la falta de edad del que habia elegido para exercerle; y atendiendo a lo que referri aora de la capacidad de D.n Francscio fernando de Nauarrete su hijo mayor: me he conformado con V[uest]ro pareçer en esta parte; dareis la orden que conuenga para que se le siente la dha Plaça de Interprete de la lengua Arauiga».
}

administración de la monarquía mediante sus quehaceres lingüísticos y en calidad de miembros de una nueva elite burocrática durante el siglo XVI. Aunque la historia de esta familia de traductores y sus servicios en el Consejo de Estado son bien conocidos, sus lazos con la política árabe de los Austrias merecen más atención.

Los Gracián desempeñaron un papel importante al manejar parte de la correspondencia epistolar de la alta diplomacia de la Monarquía Católica. Diego Gracián de Alderete fue un humanista vallisoletano cuyos estudios le llevaron a estudiar en París y Lovaina. Dominaba el francés, el italiano, el flamenco, el griego y el latín. De vuelta a España en 1527, se hizo con el título de «secretario políglota» y se puso al servicio de nobles y ministros en la corte (Cáceres Würsig, 2004b: 613). Se ocupó de la gestión del papeleo redactado en latín y griego. Por una parte, se dedicó a cuidar de la reputación de los Austrias mediante la gestión y presentación de información contenida en la correspondencia oficial. Por otra, se afanó en realizar traducciones al castellano de obras literarias e históricas escritas en latín y griego. El catálogo de sus traducciones literarias contiene obras compuestas por autores antiguos y cristianos tales como Jenofonte, Tucídides, Isócrates, Plutarco y san Ambrosio. Esta lista incluye también dos traducciones de obras contemporáneas: La Coronación Imperial con todas sus ceremonias traduzidas de latin en lengua castellana (1530), y La conquista de África en Berbería (1558) por Juan Calvete de Estrella. Estas obras y sus traducciones reflejan el cuidado con el cual Diego Gracián tradujo la historia contemporánea de los hechos imperiales de Carlos $\mathrm{V}$ para el público español e internacional.

Los Gracián se presentaron como guardianes de las narrativas, que sostenían a través de documentos administrativos y obras literarias conectados con las políticas de reputación de la Mo- 
narquía Hispánica. A primera vista, las tareas de traducción llevadas a cabo por los Gracián tienen poco que ver con la política árabe de los Austrias. No obstante, el papel que Diego Gracián desempeñó en el Consejo de Cruzada así como su traducción de la memoria de la conquista de Mahdía (actualmente en Túnez) en 1550, afianzó la influencia de la familia sobre la política árabe de los Austrias en el Mediterráneo. Las trayectorias profesionales de sus descendientes reforzaron dicha influencia.

Diego Gracián se aseguró de que sus hijos perpetuasen su memoria al heredar sus cargos. En 1564, Diego pidió al rey que su título de secretario de interpretación de lenguas fuese transmitido a su hijo Antonio — «tan hábil como yo o más» ${ }^{30}$ Desde entonces, Antonio disfrutó de una carrera burocrática imparable hasta su muerte prematura en 1576. Además de su cargo como secretario de interpretación de lenguas, Antonio recibió en 1571 el «título de secretario del rey don Felipe II» así como otro título de secretario y bibliotecario de la Real Biblioteca de San Lorenzo de El Escorial en 1574 (Andrés, 1962: 7-9).

A pesar de que tanto Diego como Antonio nunca supieron árabe, aseguraron que dicha lengua tomase su justo lugar en las prácticas y fuentes administrativas de la Monarquía. Por ejemplo, mediante su labor como bibliotecario, Antonio Gracián influyó sobre la política árabe desde el corazón de la monarquía: El Escorial. Fue él quien acogió en el Escorial la biblioteca del humanista Juan Paéz de Castro (1512-1570), incluidos sus libros arábigos, de los que haría inventario otro humanista e historiador, Ambrosio de Morales, en $1571^{31}$. Antonio se ocupó también de la conservación del estandarte otomano cap-

\footnotetext{
30 «Carta de Diego Gracián quejándose de su pobreza y renunciando el oficio en su hijo», AGS Estado Leg. 144, f. 331, 15 septiembre, 1564 .

3I AGS Cámera, Libros de Cédula, 146, ff. 347-347v. «Del oficio sobre los libros del Doctor Páez, 2 Octubre, 1571.»
}

turado durante la batalla de Lepanto. Fue en su 169 casa donde Luis del Mármol Carvajal compuso con la ayuda de unos cautivos la primera traducción de las leyendas árabes islámicas inscritas sobre el estandarte (Cabanelas, 1991: 126-127). Antonio recomendó también al morisco Alonso del Castillo - heredero del puesto granadino de trujamán mayor de Alonso Venegas y romanceador durante la guerra de las Alpujarras tal y como lo había sido Alonso de Venegas Renfigo- para la catalogación de los libros árabes en El Escorial (Morata, 1934: 95-96).

El hermano más afamado de esta generación resultó ser Jerónimo Gracián de la Madre de Dios (1547-1614), el confesor de santa Teresa de Ávila. Jerónimo también desempeñó un papel significativo en la política árabe de los Austrias a través de sus actividades mediterráneas y su influencia sobre proyectos editoriales, algunos relacionados con las obras de sus hermanos. Después de su etapa en Ávila, Jerónimo Gracián participó en varias misiones mediterráneas, las cuales fueron recordadas en las obras que imprimió. Jerónimo fue cautivo en Túnez entre 1593 y 1595 y fue allí donde aprendió algo de árabe al lado de un renegado español (Ricard, 1956: 45; Mármol, 1619: 88r y 123v). Esta experiencia le permitió componer un abecedario en cinco lenguas: griega, hebrea, «Bozna», arábiga y latina (Mármol, 1619: 125v). Después de su rescate en 1595, su hermano Tomás Gracián - quien heredó el puesto de secretario de Latín y Cruzada después de la muerte de Antonio- aprobó una traducción castellana de la historia de la primera cruzada en Tierra Santa de Guillermo de Tiro, la Historia de la guerra sacra de Jerusalén, de la tierra de promisión, y casi de toda la Siria recuperada por los cristianos ${ }^{32}$. Es difí-

$3^{2}$ BNE ms. 8550. Guilielmus de Tyro, Historia de la guerra sacra de Jerusalén, de la tierra de promisión, y casi de toda la Siria recuperada por los cristianos [...] traducida del italiano por Juan Benítez de León [aprobado 8 octubre, Tomás Gracián Dantisco]. 
170 cil descartar la posibilidad de una conexión en la mente de los lectores de esta traducción entre la presencia y labor de los españoles franciscanos actualmente en Tierra Santa y sus compañeros en Marruecos $^{33}$. En 1597 Jerónimo Gracián redactó sus memorias en «defensa de la Fe» en su Tratado de la redención de Cautivos. Este tratado pasó por la imprenta en Bruselas en 1609 el mismo año en que empezó la expulsión de los moriscos en España (Bunes, 2017: 48-49).

La intervención de los Gracián en la política árabe no se limitó a la publicación de este tratado. En 1601 Jerónimo fue enviado a Marruecos por el papa para intervenir en la diplomacia marroquí y llevar una carta real al sultán. En Marruecos, Gracián coincidió con otros agentes ibéricos e italianos de Felipe III. Aunque Jerónimo fue un fraile misionero encargado de rescatar cautivos, participó en actividades diplomáticas formales e informales entre Marruecos y varios poderes europeos. A través de su hermano, «el secretario Gracián» (Tomás en esta época), Jerónimo remitía a Felipe III relaciones detalladas sobre las actividades marroquíes ${ }^{34}$. Mientras estuvo en Marruecos, el alcaide de Tetuán estaba convencido de que Jerónimo Gracián trabajaba para Felipe III como uno de sus espías. Jerónimo tejió una compleja red de contactos con agentes y autoridades españolas al entrar en contacto con el duque de Medina Sidonia - el noble andaluz encargado de la mayoría de los asuntos berberiscos- - Negoció para que el duque prestase ayuda a Felipe III en sus negociaciones con el sultán Aḥmad al-Manșūr (Bunes y Alonso,

\footnotetext{
33 Es un asunto distinto, pero queda relevante que las órdenes enfocadas en la redención de cautivos y en particular los Franciscanos priorizaban el estudio de le lengua árabe para sus negociaciones en Marruecos y Tierra Santa. Véase por ejemplo Lourido, 2000 y 2006.

34 BNE ms. 18554, «Relación del Padre Fray Gerónimo Gracián sobre cosas de Berbería» (1602).
}

2006: 13). Luego, en 1595, estuvo involucrado en las negociaciones relacionadas con la venida de dos príncipes sa 'díes a la península ibérica. De vuelta a España y en los alrededores de 1604, fue invitado a la corte de los archiduques Isabel y Alberto en Bruselas en 1607. Llevó consigo la traducción castellana que su padre, Diego, hizo de la crónica latina que el historiador y tutor real, Calvete de Estrella (1520-1593), había compuesto sobre la conquista de Mahdía por Carlos V en 1550. Con este libro en mano y armado de sus propias experiencias africanas, Jerónimo hizo imprimir su Tratado de redención de cautivos, y se puso a escribir su autobiografía, la Peregrinación de Anastasio, antes de morir en 1614. Fue gracias al sistema europeo de cortes pertenecientes a los Austrias como Jerónimo logró prorrogar y actualizar una memoria de las cruzadas imperiales en el Norte de África a la par que se aseguraba de que dicha historia fuese ligada a la de su familia. Así, sin recurrir de manera directa a la traducción árabe-castellana de índole administrativa, los Gracián intervinieron de forma directa en la política árabe de los Austrias en el norte de África.

La Peregrinación quedó manuscrita hasta el siglo Xx, pero Andrés de Mármol utilizó su contenido —incluidos los episodios africanos — para incorporar información biográfica sobre Jerónimo Gracián y su familia en su Excelencias, vida, y trabajos del padre fray Gerónimo Gracián (Andrés de Mármol, 1619: 70r-94v, 100v; Bunes y Alonso, 2006: 10). Esta biografía se adentraba en los hechos de la familia Gracián y en los servicios lingüísticos que sus miembros ofrecieron a la corona (Mármol, 1619: 5r-11r). La obra de Mármol fue muy apreciada por los Gracián, hasta el punto de que figuró en la biblioteca del sobrino de Jerónimo, él también secretario de interpretación de lenguas, Francisco Gracián Berruguete (fl. 1633-1678) (Barrio Moya, 2006: 700; RAH E-21, f. 64v). En El Secretario del Rey, obra publi- 
cada en 1620, Francisco Bermúdez presentó a los Gracián como oficiales modélicos a cargo de la «cruzada y interpretación de lenguas» (Bermúdez, 1620: 47r-48r). Al elevar al rey una petición en 1642, Francisco Gracián se refirió a este libro $^{35}$. Relaciones, memoriales, historias y otros muchos textos acabaron formando un sistema de referencias que se autoalimentaba. Este sistema aseguró la promoción de los servicios de los Gracián a través de varias generaciones.

Los Gracián no fueron la única familia reconocida por su participación en la defensa y gestión de la Monarquía por parte de los historiadores contemporáneos. En una obra anterior a $E l \mathrm{Se}$ cretario del Rey, la publicación de Las antigüedades de Granada, permitió a Bermúdez celebrar cuatro generaciones de Venegas, «cristianos viejos de moros», al lado de los Mendoza como «los hijos desta ciudad, que han seruido al Rey de Generales, Alcaydes, Castellanos, y Capitanes» (1608: 142v-143r). Esta corografía presentaba a los Venegas y a los Mendoza como los defensores de su «patria» durante las guerras granadinas y mediterráneas. Como haría en $E l$ secretario cuando construía el perfil de los Gracián, Bermúdez asoció en su obra el ascenso social de los Venegas con sus servicios lingüísticos y su contribución en tareas administrativas relacionadas con la gestión del dominio territorial de los Austrias en Granada y sus alrededores. En los dos casos, Bermúdez pone de manifiesto los servicios de los Venegas y de los Gracián, explicando cómo sus historias convergieron a través del cauce de la historia general de la monarquía.

Francisco Gracián no dejó de remitir peticiones al rey solicitándole mercedes. En 1672 el Consejo de Estado recibió otra petición con un recorrido detallado de los servicios de su familia

35 Relación de los servicios de don Francisco Gracián Dantisco Verruguete, RAH Salazar y Castro, E-21, f. 65r. y daba cuenta de los «270 años» de servicio co171 lectivo acumulado que su familia había prestado a la Corona desde el nombramiento de Diego en $1539^{36}$. Francisco era el hijo de Tomás, quien había continuado con el cargo de secretario de interpretación de lenguas hasta su muerte en 1621. Tomás ejerció además como censor literario, tal y como su hermano Lucas (Marín Cepeda, 2010; Morreale, 1962). En 1619, por ejemplo, Tomás censuró una obra del dramaturgo, Antonio Mira de Amescua, titulada El mártir de Madrid. Amescua era uno de los miembros de la Academia Venegas en Granada. Tomás no fue el único Gracián ligado al mundo del teatro del Siglo de Oro. Lucas Gracián también fue escritor y censor literario. Además de traducir en 1584 la obra de Giovanni della Casa, Galateo español, destierro de ignorancias, cuaternario de avisos, Lucas aprobó La Galatea de su amigo Cervantes, antiguo cautivo de Argel $^{37}$. Los hijos de Tomás -Alonso Gracián Berruguete y Francisco Gracián Berruguete - recibieron uno después del otro el cargo de intérprete real. La temprana muerte de Alonso en 1636 dejó la herencia profesional en manos de Francisco, quien ocupó puestos destacados hasta su muerte en 1678 . Desde 1633, Francisco ya trabajó como secretario de interpretación de lenguas, y desempeñó cargos especiales para los consejos de Estado,

${ }^{6}$ El Consejo recomendó como recompensa la capellanía de los Reyes Nuevos de Toledo para el hijo de Francisco, Pedro Gracián de Solórzano, y el rey aprobó la recomendación. Por parte del Consejo de Estado. Por don Francisco Gracián Berruguete secretario de la Interpretación de Lenguas. AGS Estado, Legajo 4117, n. 407, s. f. 3 agosto, 1672.

37 Miguel de Cervantes, Primera parte de la Galatea, Alcalá de Henares: Juan Gracián, 1585, f. 2v. A pesar del homónimo, no nos consta que Juan Gracián formó parte de la misma familia de los Gracián humanistas, consejeros y traductores. Véase la entrada por Julián Martín Abad en el Diccionario Bibliográfico Español de la RAH (http://dbe.rah.es/biografias/60500/juan-gracian, consultado 21.12.20). 
172 Italia y Flandes ${ }^{38}$. En esta misma época los Gracián pedían hábitos de Santiago, tal y como los Sotomayor, y a lo largo del siglo XVIII un gran número de traductores oficiales (Gracianes y no Gracianes) se hicieron miembros de la Orden (Cáceres Würsig, 2004b: 612-615).

Durante más de dos siglos, los Gracián mantuvieron su influencia sobre el gobierno por palabras de la Monarquía y su política árabe. Lo hicieron tanto a nivel político como cultural. No dudaron tampoco a la hora de intervenir en «asuntos orientales». Por ejemplo, en 1636, Francisco Gracián Berruguete se encargó de la traducción castellana de un firmán otomano que acompañaba una carta (junta a su traducción italiana) del provincial español de los franciscanos en Tierra Santa. Si bien alejado de la vida cotidiana de la Palestina otomana, fue un Gracián quien —en calidad de «Secretario de la Interpretación de Lenguas»- aseguró que este documento llegase a ser considerado por Felipe $\mathrm{IV}^{39}$. En la práctica, los límites entre traductores de Estado y miembros de la secretaría de interpretación de lenguas eran porosos. Por ejemplo, el mismo Francisco Gracián Berruguete recibió unos pagos en 1658 por parte del Consejo de Estado (Cáceres Würsig, 2004b: 617). En 1672 una merced fue concedida después de que Pedro Gracián de Solorano, hijo de Francisco, elevase un memorial para pedir el título de capellán de «los Reyes Nuevos» en Toledo. El Consejo de Estado acabó recomendándole para el puesto ${ }^{40}$.

\footnotetext{
${ }^{8}$ Relación de los servicios de don Francisco Gracián Dantisco Verruguete, RAH Salazar y Castro, E-21, f. 64r.

39 BNE ms 2367, ff. 310-311v. Copia de la sentencia que el Gran Turco dio en primero de Abril deste año de 1636 en fauor de los Religiosos de nuestro seráfico Padre san Francisco, en los pleitos con los Griegos [impreso].

$4^{\circ}$ AGS, Estado, Legajo 4117. Carta del consejo de Estado a don Manuel de Moscoso, 15 noviembre, 1672.
}

Al morir en 1678, Francisco Gracián Berruguete había cumplido más de cuatro décadas de servicio lingüístico, casi tanto como su abuelo Diego. Aunque había participado en traducciones de «lenguas orientales», el inventario de su biblioteca solo atestigua su conocimiento del latín, griego, francés, italiano, flamenco y portugués. La memoria de su tío, Jerónimo Gracián, ocupaba un lugar destacado entre los libros de su biblioteca, incluyendo varios ejemplares de las obras y cartas de santa Teresa (Barrio, 2006: 699-701). Francisco y sus hijos tuvieron a bien conservar e incrementar la historia de los servicios de su familia, y más particularmente de los servicios relacionados con la política árabe de la Monarquía. En 1652, el hijo de Francisco, Antonio Gracián y Gutiérrez de Solórzano, «Secretario de S.M. y de la Interpretación de Lenguas», recibió su hábito de Santiago ${ }^{41}$. Su hijo Felipe Antonio Gracián de Pereda heredó el título de traductor en la secretaría de interpretación de lenguas. En 1700 recibió otro hábito de Santiago (García Carrafa y García Carrafa, 1917: 37). En los alrededores del año 1729, otro Gracián siguió ejerciendo como traductor a pesar de que la administración borbónica había reformado los despachos de traducción e interpretación basándose en el modelo europeo de los jeunes de langues franceses y de los Sprachknäben en Viena (Cáceres Würsig, 2012). A lo largo de tres siglos, y a través de diferentes cortes y modelos, los Gracián se adaptaron a los cambios tocantes al ejercicio de la traducción de Estado sin menospreciar sus colaboraciones con el mundo de la traducción arábiga.

\footnotetext{
${ }^{\text {4 }}$ AHN OOMM Caballeros Santiago, expendientillo, 3442 (septiembre 1652).
} 


\section{CONCLUSIONES}

Entre los siglos XVI y XVII, los Austrias españoles se tomaron muy en serio la cuestión de la traducción como herramienta de gobierno. A lo largo del reinado de Felipe IV (r. 1621-1665), las genealogías de los servicios de diferentes linajes y dinastías de traductores alcanzaron su auge dentro de la circulación robusta de relaciones de servicios y méritos por todo el imperio. Fue a partir de los años cuarenta del siglo XVII cuando estos linajes de traductores estatales trataron de consolidar su ascenso social.

La interpretación de lenguas y en particular la traducción de fuentes «orientales» ofreció un nexo de comunicación entre las cortes de Madrid y Viena. No hace falta aquí recodar que traducción y multilingüismo jugaron un papel clave en el Santo Imperio y en el Imperio Austrohúngaro hasta la primera guerra mundial (Reiter, 2015; Wolf, 2015). Los Austrias intercambiaron traductores oficiales a lo largo de los reinados de Felipe IV y de Carlos II. Por ejemplo, Vicente Bratutti o Brattutovic, traductor imperial y experto en lengua otomana circuló entre las dos cortes. El envío de Brattuti a España coincidió con la llegada de la primera embajada oficial otomana a Madrid en 1649 (Conde Pazos, 2011) y Bratutti remplazó a los Gracián a la hora de traducir cartas otomanas. Dicha embajada fomentó traducciones de un amplio elenco de fuentes árabes en España. Dos volúmenes de las fábulas de Kalila wa-Dimna fueron publicados en español en 1654 y en 1658 bajo el título: Espejo político y moral para príncipes y ministros. Mientras Gurmendi tradujo fuentes persas desde sus versiones árabes traducidas en castellano, Brattuti hizo lo propio traduciendo fuentes árabes desde sus versiones otomanas. Como los demás ejemplos, los Bratutti quisieron también establecerse como una dinastía lingüística en el interior de la
Monarquía Hispánica. El hijo de Bratutti, Gerónimo, pidió un cargo de traductor en Madrid en 1690 (Reiter, 2015: 129-130).

A lo largo de la Edad Moderna las dinastías administrativas-lingüísticas de familias de traductores desempeñaron un papel clave en la afirmación del organigrama estatal de los Austrias españoles. Los Venegas, los Sotomayor y los Gracián sostuvieron la continuidad de la política árabe de los Austrias, aunque no lo hicieron siempre a través del manejo de la lengua arábiga. Al analizar las trayectorias individuales de algunos miembros de estas tres familias, parece que la política árabe de los Austrias no se ciñó de manera exclusiva al ámbito cortesano ni a sus fronteras. La vida política de la Monarquía Hispánica dependió en gran parte de trabajos lingüísticos continuos. Estos fueron a menudo invisibles (Venuti, 2008), pero las familias que los llevaron a cabo supieron sacar provecho de esta situación. Cultivaron el prestigio y la reputación de la Monarquía y de sus linajes mediante la obtención de gracias, mercedes y privilegios. Estos ejemplos demuestran que la traducción, y no solo la lengua, seguía siendo la compañera del imperio, especialmente a la hora de conquistar, integrar, neutralizar, conservar y promover las políticas lingüísticas de los Austrias tanto dentro de la península ibérica como fuera de esta.

\section{REFERENCIAS}

Abad Merino, Mercedes (2011): «La traducción de cartas árabes en un pleito granadino del siglo XvI. El fenómeno del romanceado como acto judicial: Juan Rodríguez y Alonso del Castillo ante un mismo documento», Al-Qanțara, 32/2 (2011), 481-518.

Almosnino, Moses (1638): Extremos y grandezas de Constantinopla, Madrid: Francisco Martínez.

ANDRÉs, Gregorio (1962): «Diurnal de Antonio Gracián, Secretario de Felipe II», En Documentos Para La Historia Del Monasterio de San Lorenzo El Real de 
174 El Escorial, Tomo 5, El Escorial: Imprenta del Real Monasterio.

BAEZA, Hernando de (1868): «Las cosas que pasaron entre los reyes de Granada desde el tiempo de el Rrey don Juan de Castilla, segundo de este nombre, hasta que los católicos reyes ganaron el rreyno de Granada», en Emilio Lafuente y Alcántara (ed.), Relaciones de algunos sucesos de los últimos tiempos del reino de Granada, Madrid: Rivadeneyra, 1-44.

Barrio Moya, José Luis (2006): «La biblioteca del erudito madrileño Francisco Gracián Berruguete, 'secretario de la ynterpretación de lenguas' de Felipe IV y Carlos II», Anales del Instituto de Estudios Madrileños, 46, 693-706.

Bermúdez de Pedraza, Francisco (1608): Las antigüedades de Granada, Madrid: Luís Sánchez.

Bermúdez de Pedraza, Francisco (1620): El secretario del rey, Madrid: Luís Sánchez.

Bunes, Miguel Ángel (2017): «Jerónimo Gracián Dantisco», en David Thomas y John Chesworth (eds.), Christian-Muslim Relations: A Bibliographical History, v. 9 (Western and Southern Europe, 1600-1700), Leiden-Boston: Brill, 47-49.

Cabanelas, Darío (1991): El morisco Alonso del Castillo, Granada: Universidad de Granada.

CÁCERES WÜRSIG, Ingrid (2004a): Historia de la traducción en la administración y en las relaciones internacionales en España (ss. XVI-XIX), Madrid: Vertere.

CÁCERES WÜrSIG, Ingrid (2004b): «Breve historia de la Secretaría de Lenguas,» META, 49/3, 609-628.

CÁCERES WÜrsIG, Ingrid (2012): «The jeunes de langues in the eighteenth century: Spain's first diplomatic interpreters on the European model», Interpreting, 14/2, 127-144.

Conde Pazos, Miguel (2011): «La embajada turca en Madrid y el envío de Alegreto de Allegretti a Constantinopla (1649-1650)», Libros de las Cortes, 3, 10-17.

Corbalán de Celis y Durán, Juan (2015): «Unas notas sobre los Álvarez de Sotomayor y Antonio de Villalba, gobernadores de Melilla», Akros 14: 15-28.

DAKHLIA, Jocelyne (2008): Lingua Franca. Histoire d'une langue métisse en Méditerranée, París: Actes Sud.

Echevarría Arsuaga, Ana (2013): «Trujamanes and Scribes: Interpreting Mediation in Iberian Royal
Courts», en M. von der Höh, J. R. Oesterle \& N. Jaspert (eds.), Cultural Brokers between Religions, Paderborn: Verlag Ferdinand Schöningh, 73-94.

Feria García, Manuel C. y Juan Pablo Arias Torres (2005): «Un nuevo enfoque en la investigación de la documentación árabe granadina romanceada», Al-Qanțara, 26/1, 191-247.

Feria García, Manuel C. y Juan Pablo Arias Torres (2004): «Escrituras árabes granadinas romanceadas: una mina a cielo abierto para la historia de la traducción y la traductología», Trans: Revista de traductología, 8: 179-184.

Feros, Antonio (2014): «Rhetorics of the Expulsion», en Mercedes García-Arenal y Gerard Wiegers (eds), The Expulsion of the Moriscos from Spain: A Mediterranean Diaspora, Leiden: Brill, 60-101.

FLoristáN, José M. (2013): «Diego de Urrea (c. 1559-octubre de 1616), traductor de árabe, turco y persa en la corte de España: Nuevas noticias biográficas», Boletín de la Real Academia de la Historia, 210/2, 227-274.

FLoRISTÁN, José M. (2014): «Francisco de Gurmendi, Intérprete de árabe, turco, y persa, en la corte de Felipe II», Boletín de la Real Academia de la Historia, 211/2, 357-374.

GALÁN SÁNCHEZ, Ángel (2008): «"Fuqaha” y musulmanes vencidos en el reino de Granada (14851520)», en Ana Echevarría Arsuaga (coord.), Biografías mudéjares o La experiencia de ser minoría: biografías islámicas en la España cristiana, 329-384.

GalÁN SÁNCHEZ, Ángel (2016): «Identidad e intermediarios culturales. La lengua árabe y el fisco castellano tras la conquista del Reino de Granada», Edad Media, 17: 109-132.

Gallego Burín, Antonio, y Alfonso Gámir Sandoval (1968): Los moriscos del Reino de Granada: según el Sinodo de Guadix de 1554. Granada: Universidad de Granada.

García-Arenal, Mercedes (2009): «The Religious Identity of the Arabic Language and the Affair of the Lead Books of the Sacromonte of Granada», Arabica, 56/6, 495-528.

García-Arenal, Mercedes (2009): «Moriscos and Indians: A Comparative Approach», en Geert Jan van Gelder y Ed de Moor (eds), Orientations, 1, 39-55. 
García-Arenal, Mercedes y Fernando Rodríguez Mediano (2013): The Orient in Spain: Converted Muslims, the Forged Lead Books of Granada, and the Rise of Orientalism, trad. Consuelo López-Morillas, Leiden: Brill.

García-Arenal, Mercedes; Fernando Rodríguez Mediano y Rachid El Hour (2002): Cartas marruecas: documentos de Marruecos en archivos españoles, Madrid: CSIC.

García-Arenal, Mercedes y Gerard Wiegers. (2007): Un hombre en tres mundos: Samuel Pallache, un judío marroquí en la Europa protestante y en la católica, México: Siglo XXI.

García Carraffa, Alberto and Arturo García Carraffa (1917): Enciclopedia heráldica y genealógica, tomo LIX, Madrid: Artes Gráficas-Roberto López-Hileras.

García Figueras, Tomás y Carlos Rodríguez Joulia de Saint Cyr (1973): Larache: Datos para su historia en el siglo XVII, Madrid: CSIC.

García LujÁN, José Antonio (2010a): «Genealogía del linaje Granada Venegas desde Yusuf IV, rey de Granada (1432) hasta la extinción de la varonía del linaje (1660)», en J. A. García Luján (ed.), Simposio Nobleza y Monarquía: Los linajes nobiliarios en el Reino de Granada, Siglos XV-XVI: El linaje Granada Venegas, Marqueses de Campotéjar, Húescar: Asociación Cultural Raigadas, 13-43.

García LujÁn, José Antonio (2010b): Documentos de la Casa de Granada: Linaje Granada Venegas, marqueses de Campotéjar, Granada: Asociación Cultural Raigadas.

GARRARD, Keith (1954): «The Original Memorial of Don Francisco Núñez Muley», Atlante, 4, 199-226.

Garrido Aranda, Antonio (1979): La organización de la Iglesia en el Reino de Granada y su proyección en Indias. Siglo XVI, Sevilla: Escuela de Estudios Hispano-americanos.

GILBERT, Claire (2020): In Good Faith: Arabic Translation and Translators in Early Modern Spain, Filadelfia: University of Pennsylvania Press.

GILBERT, Claire (2018): «Transmission, Translation, Legitimacy and Control: The Activities of a Multilingual Scribe in Morisco Granada», en Giuseppe Mandala e Inmaculada Pérez Marin (eds.), Multilingual and Multigraphic Manuscripts and Docu- ments of East and West, Piscataway, N.J.: Gorgias Press, 425-462.

GonZÁlez VÁZqueZ, José (2010): «La academia Granada- Venegas en la Granada del siglo xvi y comienzos del XVII», en J. A. García Luján (ed.), Simposio Nobleza y Monarquía: Los linajes nobiliarios en el Reino de Granada, Siglos XV-XVI: El linaje Granada Venegas, Marqueses de Campotéjar, Húescar: Asociación Cultural Raigadas, 413-28.

Gracián de la Madre de Dios, Jerónimo (2006): Tratado de la rendención de cautivos, ed. Miguel Ángel Bunes y Beatriz Alonso Acero, Madrid: Espuela de Plata.

Hershenzon, Daniel (2019): «Doing Things with Arabic in the 17th- Century Escorial», Philological Encounters, 4, 151-89.

Hershenzon, Daniel (2014): «Traveling Libraries: The Arabic Manuscripts of Muley Zidan and the Escorial Library», Journal of Early Modern History, 18, 535-58.

Hess, Andrew (1978): The Forgotten Frontier: A History of the Sixteenth-Century Ibero-African Frontier, Chicago: University of Chicago Press.

López Nevot, José Antonio (2010): «Los Granada Venegas, regidores, alguaciles mayores de Granada y procuradores de la ciudad en las cortes de Castilla (siglos XV-XVII)», en J. A. García Luján (ed.), Simposio Nobleza y Monarquía: Los linajes nobiliarios en el Reino de Granada, Siglos XV-XVI: El linaje Granada Venegas, Marqueses de Campotéjar, Húescar: Asociación Cultural Raigadas, 325-360.

Llopis MenA, María Isabel (2016): Teoría política árabe y persa en la corte de Felipe III, Tesis Doctoral, Universidad de Alicante.

Lourido DíAz, Ramón (2000): «El estudio de la lengua árabe entre los Franciscanos de Marruecos (siglos XIII-XVIII)», Archivo Ibero-Americano, 60: 3-34.

LouRIDo DíAz, Ramón (2006): El estudio del árabe entre los franciscanos españoles en Tierra Santa. Siglos XVII$X I X$, Madrid: Editorial Cisneros.

Mariñó GómEZ, Primitivo (1980): Carlos V. Norte de África, Tomo II. Madrid: CSIC.

MARín CePedA, Patricia (2010): «Nuevos documentos para la biografía de Tomás Gracián Dantisco, censor de libros y comedias de Lope de Vega (I)» en 
176 Germán Vega García-Luengos, Héctor Urzáiz Tortajada (coords.), Cuatrocientos años del "Arte nuevo de hacer comedias" de Lope de Vega: actas selectas del XIV Congreso de la Asociación Internacional de Teatro Españoly Novohispano de los Siglos de Oro, Vol. 2, Valladolid: Universidad de Valladolid, 705-714.

Mármol, Andrés de (1619): Excelencias, vida, y trabajos del padre fray Geronimo Gracián de la Madre de Dios, Madrid, s.n.

Martínez Millán, José y C. Javier de Carlos Morales (1991): «Los orígenes del Consejo de Cruzada (siglo XVI)», Hispania, 51/3, 901-932.

Molina LóPez, Emilio y María Carmen Jiménez Mata (2004): Documentos árabes del Archivo Municipal de Granada. Granada: Ayuntamiento de Granada.

Morata, Nemesio (1934): «Un catálogo de los fondos árabes primitivos de el Escorial», Al-Andalus, 2/1, 87-181.

Morreale, Margherita (1962): «El “Galateo español” de Lucas Gracián Dantisco: una obra de cortesía en tono menor», Boletín de la Real Academia Española, 42/165, 47-90.

Osorio Pérez, María José y Emilio de Santiago Simón (1986): Documentos Arábigo-Granadinos Romanceados, Granada: Centro de Estudios Históricos de Granada y su Reino.

REITER, Clara (2015): In Habsburgs sprachlichem Hofdienst: Translation in den diplomatischen Beziehungen zwischen den habsburgischen Höfen von Madrid und Wien in der Frühen Neuzeit, Tesis Doctoral, Karl- Franzens-Universität Graz.

RICARD, Robert (1956): «Le père Jérôme Gratien [sic] de la mère de Dieu et sa captivité à Tunis (15931695 [sic])», Études Hispano-Africains, Tetuán: Instituto General Franco, 39-50.

Rodríguez Mediano, Fernando (2006): «Fragmentos de orientalismo del siglo XVII», Hispania, 66/222, 243-76.

Rodríguez SAlgado, María José (2008): The Changing Face of Empire, Cambridge: Cambridge University Press.

SAlicrú I Lluch, Roser (2001): «Nuevos mitos de frontera: Muhammad X el Cojo, Ali al-Amin y Ridwan Bannigas entre historiografía e historia, entre realidad y leyenda», Estudios de Frontera, 4: 487-505.
SALICRÚ I LluCh, Roser (2008): «Intérpretes y diplomáticos: Mudéjares mediadores y representantes de los poderes cristianos en la Corona de Aragón» en Ana Echevarría Arsuaga (coord.) Biografías mudéjares o La experiencia de ser minoría: biografías islámicas en la España cristiana, 329-384

Schaub, Jean- Frédéric (1999): Les juifs du roi d'Espagne: Oran 1509-1669, París: Hachette Littératures.

SECO DE LuCENA, Luis (1961): «Alamines y Venegas: Cortesanos de los Nașríes», Miscelánea de Estudios Árabes y Hebraicos, 10/1, 127-142.

Soria Mesa, Enrique (2004) «Genalogia y poder: invención de la memoria y ascenso social en la España moderna», Estudis: Revista de Historia Moderna, 30, 21-56.

Sotomayor y VALENZuela, Luís Joseph de (1670): Breve relación y compendioso epítome de la general expulsión de los Hebreos de la Iuderia de Orán, s.n.

Venuti, Lawrence (2008): The Translator's Invisibility: A History of Translation, Londres: Routledge.

VINCENT, Bernard (1993): «Reflexión documentada sobre el uso del árabe y de las lenguas románicas en la España de los moriscos (ss. Xvi-XVII)», Sharq alAndalus, 10-11, 732-748.

WaSSERMAN-SOLER, Daniel (2020): Truth in Many Tongues: Religious Conversion and the Languages of the Early Spanish Empire, College Park: Pennsylvania State University Press.

Wolf, Michaela (2015): The Habsburg Monarchy's Many-Languaged Soul: Translating and Interpreting, 1848-1918, Ámsterdam-Filadelfia: John Benjamins.

WRIGHT, Elizabeth (2009) «Narrating the Ineffable Lepanto: The Austrias Carmen of Joannes Latinus (Juan Latino)», Hispanic Review, 77/1, 71-91.

ZHIRI, Nina (2018): «A Captive Library between Morocco and Spain», en Marcus Keller y Javier Irigoyen-García (eds.), Dialectics of Orientalism, Londres: Palgrave, 17-32. 